\title{
Brugada-like syndrome presenting with monomorphic ventricular tachycardia and Brugada-type electrocardiogram unmasked by fever in an infant: a case report
}

\author{
SEMVUA B. KILONZO ${ }^{1,2}$, FAITH RINGO ${ }^{3}$, STEPHEN HUMPHREY ${ }^{3,4}$ BONAVENTURA T. MPONDO 5 and JOHN R.

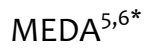 \\ ${ }^{1}$ Department of Internal Medicine, Catholic University of Health and Allied Sciences, Mwanza-Tanzania \\ ${ }^{2}$ Department of Internal Medicine, Bugando Medical Centre, Mwanza-Tanzania \\ ${ }^{3}$ Department of Emergency Medicine, Muhimbili National Hospital, Dar es Salaam, Tanzania \\ ${ }^{4}$ Global Health Service Partnership, Washington, United States of America \\ ${ }^{5}$ Department of Internal Medicine, College of Health Sciences, University of Dodoma, Dodoma, Tanzania \\ ${ }^{6}$ Muhimbili University of Health and Allied Sciences, P.O. Box 65001, Dar es Salaam
}

Correspondence E-mail: jmedaus@yahoo.com

\begin{abstract}
Brugada syndrome is an autosomal-dominant arythmogenic genetic disorder associated with mutation in the SCN5A gene. We report a case of 3-month-old Tanzanian male who was admitted at Muhimbili National Hospital in Dar es Salaam, Tanzania with severe pneumonia, high fever and monomorphic ventricular tachycardia. The patient was treated with intravenous Amiodarone. In addition, oxygen, parenteral antibiotics, antipyretics and intravenous fluids were also given. About 2 hours and 20 minute later the child stabilized. An ECG obtained shortly after termination of ventricular tachycardia showed the typical J-point and coved ST elevation typical of Brugada type I pattern. To the best of our knowledge, this is the first paediatric case with Brugada-type ECG to be reported in Sub-Saharan Africa. This case emphasizes the need to increase awareness among clinicians of clinical and genetic arythmogenic disorders. Multiple ECGs during and after febrile disorders should be performed in children who exhibit extreme tachycardia or signs of cardiac failure.
\end{abstract}

Keywords: Brugada, infant, ventricular tachycardia, electrocardiogram, Tanzania

\section{Introduction}

Brugada syndrome $(\mathrm{BrS})$ is an autosomal-dominant arythmogenic genetic disorder associated with mutation in the SCN5A gene, which encodes the cardiac sodium-channel (Chen et al., 1998). The diagnosis relies on clinical criteria in the presence of Brugada-type Electrocardiogram (ECG) (Bayés de Luna et al., 2012). This ECG pattern has been predominantly reported among Asians and white populations with only a few cases reported in individuals of African origin, and none of among children. We report a case of 3-month-old Tanzanian male who was admitted at Muhimbili National Hospital in Dar es Salaam with severe pneumonia and high fever together with monomorphic ventricular tachycardia (VT) on the ECG. Following the drug cardiovesion, ECG converted to type I Brugada pattern which later disappeared after the fever had subsided.

\section{Case report}

A 3 month-old Tanzanian male was admitted to our hospital with the diagnosis of severe bronchopneumonia with fever, difficulty in breathing and inability to feed. His past medical history

\footnotetext{
*Correspondence E-mail: jmedaus@yahoo.com
} 
was unremarkable and there was no known exposure to tuberculosis. There was no family history of heart disease of any type or sudden cardiac death. The initial assessment revealed a respiratory rate of 58 cycles per minute, temperature of $39.8^{\circ} \mathrm{C}$, heart rate of 238 beats per minute, haemoglobin oxygen saturation of $72 \%$ in room air, and blood glucose of $6.2 \mathrm{mmol} / \mathrm{l}$. Serum electrolytes $\left(\mathrm{Na}^{+}, \mathrm{K}^{+}\right.$, $\mathrm{Mg}$ and $\mathrm{Ca}^{+}$) and Thyroid function tests were all normal. An initial ECG showed monomorphic ventricular tachycardia at a rate of 233 beats per minute (Figure 1).

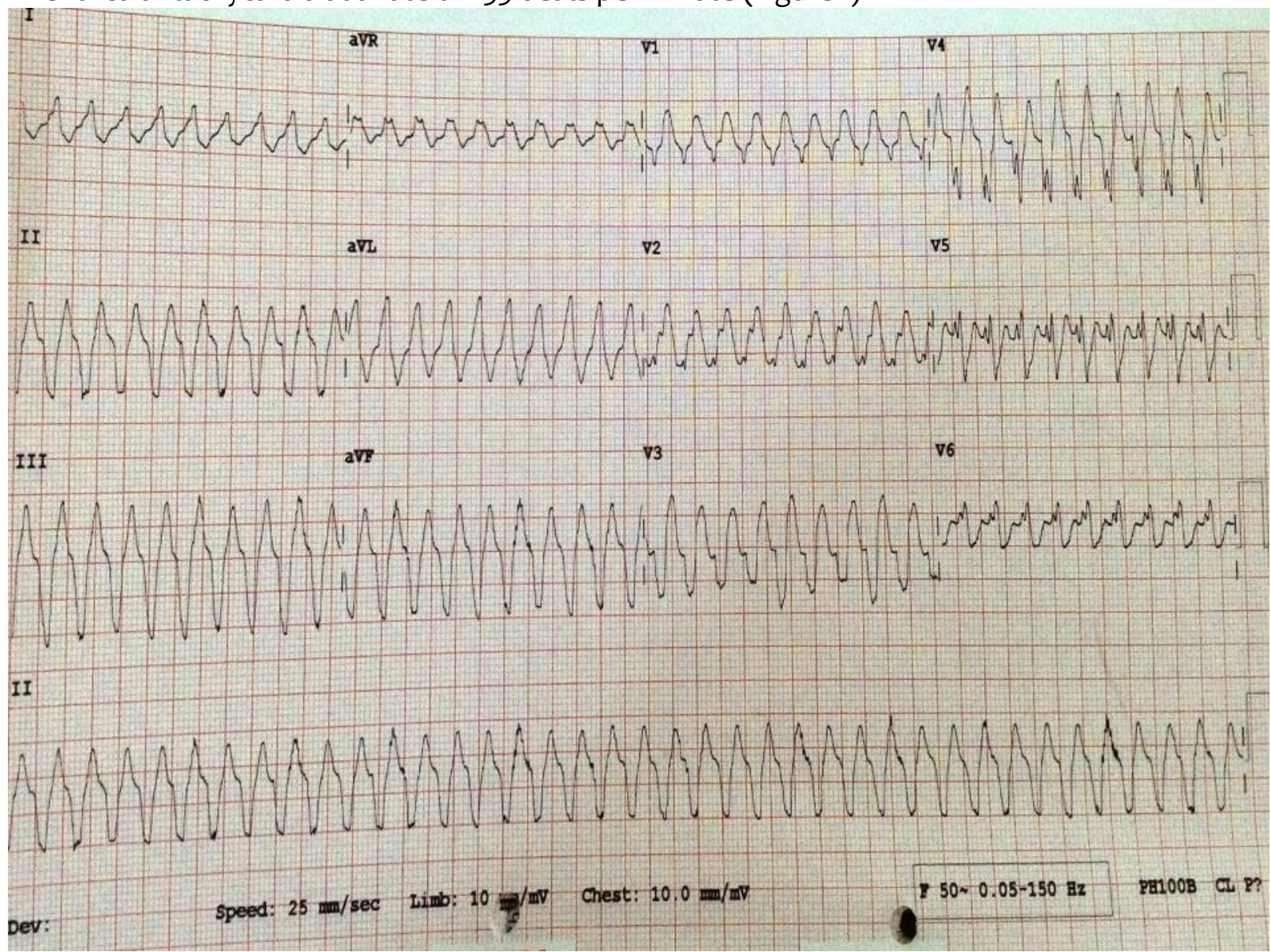

Figure 1: ECG showing monomorphic ventricular tachycardia with a heart rate of $233 \mathrm{~b} / \mathrm{min}$

Therapy was initiated with intravenous Amiodarone according to available guidelines (Zipes et al., 2006) at a dose of $5 \mathrm{mg} / \mathrm{kg}$ IV slowly (20 minutes) in both attempts. In addition, oxygen, parenteral antibiotics, antipyretics and intravenous fluids were also given. Over the ensuing 2 hours and 20 minutes the child stabilized and although ventricular tachycardia persisted, there was progressive slowing of the heart rate until the occurrence of spontaneous conversion to a junctional tachycardia at a rate of 110 beats per minute. An ECG obtained shortly after termination of ventricular tachycardia showed the typical J-point and coved ST elevation typical of Brugada type I pattern in lead V2 (Figure 2).

The child improved tremendously and amiodarone was discontinued after six hours with no recurrence of ventricular tachycardia. An echocardiogram showed no evidence of structural heart disease. He was discharged home after five days in good condition. A pre-discharge ECG, when the child was afebrile, showed junctional and atrial ectopy with no right precordial J-point or ST 
elevation. The patient was doing well three months after discharge and a repeat echocardiogram and blood chemistry remains normal.

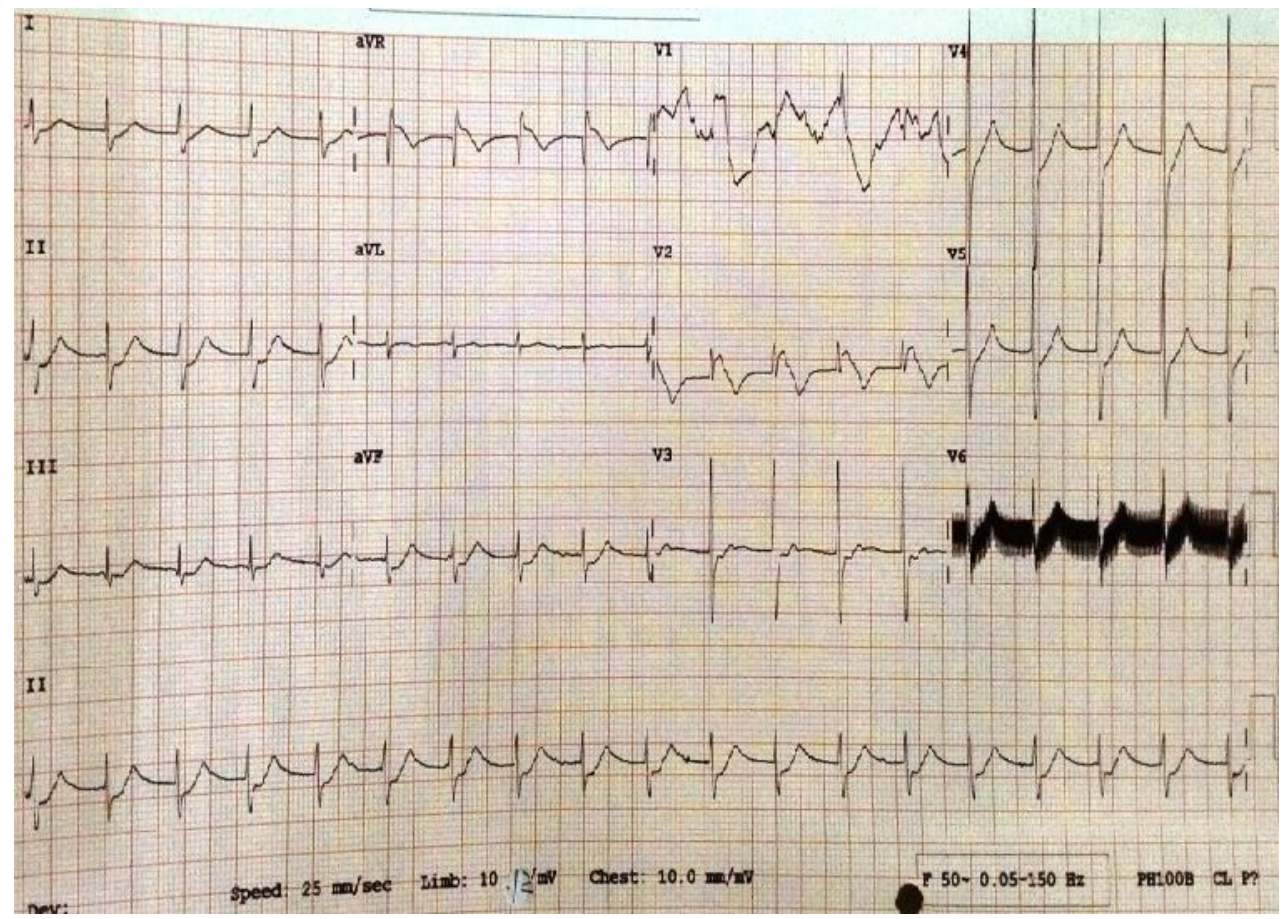

Figure 2: ECG showing J-point and coved ST elevation of Type I Brugada pattern in lead V2

\section{Discussion}

The prevalence of Brugada-type ECG in Africa is unknown although a few adult-cases of Africanorigin have been reported in Tunisia (Ouali et al., 2011), France (Bonny et al., 2008) and the United States of America (Suzuki, 2006). Although the condition is usually diagnosed among adults, paediatric cases have been reported in Europe (Priori et al., 2000; Probst et al., 2007), and Japan (Yamakawa et al., 2004). In the light of these reports, our assumption is that the condition is very rare in African children, particularly Tanzania. We also assume that most cases remain misdiagnosed or unreported due to lack of ECG machines in most of the health facilities in Tanzania and lack of awareness and knowledge on interpreting the ECGs among the clinicians. Our patient was only 3months old. His younger age and the fact that he is black African, makes the case more interesting and unique.

In the presence of the Brugada-type ECG, BrS is diagnosed if one/more of the following clinical factors are present, according to the consensus report (Bayés de Luna et al., 2012): (a) survivors of cardiac arrest, (b) presence of polymorphic ventricular tachycardia (VT), (c) history of non-vagal syncope, (d) familial antecedents of sudden death in patients younger than 45 years without acute coronary syndrome, and (e) or type 1 ST pattern in relatives.

Our patient's initial presentation was rapid monomorphic VT (Figure 1), and later coved ST elevation of Brugada-type I ECG in lead V2 after cardiovesion (Figure 2) while he was febrile. Since the monomorphic ECG pattern doesn't fulfil the usual diagnostic criteria for the BrS, there would be a necessity for electro-physiological studies including the administration of sodium- channel blockers for confirmation. A similar case has been reported in India, where the diagnosis of BrS was confirmed 
following induction by intravenous procainamide (Sastry et al., 2001). We were unable to perform EPS to our patient. Febrile state, in conjunction with other factors has been shown to unmask the Brugada pattern on the ECG and trigger arrhythmias which may have initially be concealed (Wakita et al., 2004; Antzelevitch \& Brugada, 2002; Adler et al., 2013). Fever, in our patient may have led to the exposure of his Brugada-pattern ECG as the consequent ECG post febrile condition was normal.

Therapeutic recommendations include the use of an implantable cardiac defibrillator (ICD) in all symptomatic patients with Brugada-Type I ECG. EPS with sodium channel blockage is indicated in all asymptomatic patients with type 1 Brugada ECG and ICD should be inserted only if they are ventricular arrhythmias are inducible (Antzelevitch et al., 2005). From these recommendations, it is clear that our patient would qualify for EPS. Genetic studies would also be important for the recognition of BrS mutations and differentiation from other Brugada phenocopies. Due to our limited capacity, none of these tests could be performed. Despite these diagnostic limitations, we remain concerned that our patient may be at increased risk of sudden death as it was observed in one long term follow-up study of asymptomatic individuals with Brugada-type I ECG pattern (Brugada et al., 2002). To the best of our knowledge, this is the first paediatric case with Brugadatype ECG to be reported in Sub-Saharan Africa.

\section{Conclusion}

This case emphasizes the need to increase awareness among clinicians of clinical and genetic arythmogenic disorders. Electrocardiograms should be available to clinicians in primary care as well as referral settings. There should be more widespread instruction in basic electrocardiographic interpretation and arrhythmia interpretation. Multiple ECGs during and after febrile disorders should be performed in children who exhibit extreme tachycardia or signs of cardiac failure.

\section{Competing interests}

Authors declare that they have no competing interests.

\section{Authors' contribution}

JRM, FR and SH managed the patient and collected the clinical information. SBK was involved in literature search and manuscript writing. All authors critically revised the manuscript and approved the final draft.

\section{Acknowledgements}

We thank the staff of the Emergency Department and Cardiology Unit of the Muhimbili National Hospital for their cooperation. We also thank the legal guardian (Mother) of this patient for allowing us to share this case.

\section{Consent}

Written informed consent for publication of this case report and the accompanying images was obtained from the legal guardian of this patient (mother).

\section{References}


Adler, A., Topaz, G., Heller, K., Zeltser, D., Ohayon, T., Rozovski, U., Halkin, A., Rosso, R., Ben-Shachar, S., Antzelevitch, C. \& Viskin, S. (2013) Fever-induced Brugada pattern: how common is it and what does it mean? Heart Rhythm 10, 1375-1382.

Antzelevitch, C., Brugada, P., Borggrefe, M., Brugada, J., Brugada, R., Corrado, D., Gussak, I., LeMarec, H., Nademanee, K., Perez Riera, A.R., Shimizu, W., Schulze-Bahr, E., Tan, H. \& Wilde, A., (2005) Brugada syndrome: report of the second consensus conference. Heart Rhythm 2, 429-440.

Antzelevitch, C. \& Brugada, R. (2002) Fever and Brugada syndrome. Pacing and Clinical. Electrophysiol. $25,1537-1539$.

Bayés de Luna, A., Brugada, J., Baranchuk, A., Borggrefe, M., Breithardt, G., Goldwasser, D., Lambiase, P., Riera, A.P., Garcia-Niebla, J., Pastore, C., Oreto, G., McKenna, W., Zareba, W., Brugada, R. \& Brugada, P. (2012) Current electrocardiographic criteria for diagnosis of Brugada pattern: a consensus report. Journal of Electrocardiology 45, 433-442.

Bonny, A., Tonet, J., Fontaine, G., Lacotte, J., Coignard, E., Duthoit, G., Hidden-Lucet, F., Charron, P., Brugada, P. \& Frank, R. (2008) Brugada syndrome in pure black Africans. Journal of Cardiovascular Electrophysiology 19, 421-426.

Brugada, J., Brugada, R., Antzelevitch, C., Towbin, J., Nademanee, K. \& Brugada, P. (2002) Long-term follow-up of individuals with the electrocardiographic pattern of right bundle-branch block and ST-segment elevation in precordial leads V1 to V3. Circulation 73-78.

Chen, Q., Kirsch, G.E., Zhang, D., Brugada, R., Brugada, J., Brugada, P., Potenza, D., Moya, A., Borggrefe, M., Breithardt, G., Ortiz-Lopez, R., Wang, Z., Antzelevitch, C., O’Brien, R.E., SchulzeBahr, E., Keating, M.T., Towbin, J.A. \& Wang, Q. (1998) Genetic basis and molecular mechanism for idiopathic ventricular fibrillation. Nature 392, 293-296.

Ouali, S., Boughzela, E., Haggui, A., Haouala, H., Battikh, K., Ben Ameur, Y., Kraiem, S., Krichen, S., Hentati, M. \& Kammoun, S. (2011) Clinical and electrophysiological profile of Brugada syndrome in the Tunisian population. Pacing and Clinical Electrophysiology 34, 47-53.

Priori, S.G., Napolitano, C., Giordano, U., Collisani, G. \& Memmi, M. (2000) Brugada syndrome and sudden cardiac death in children. Lancet 355, 808-809.

Probst, V., Denjoy, I., Meregalli, P.G., Amirault, J.-C., Sacher, F., Mansourati, J., Babuty, D., Villain, E., Victor, J., Schott, J.-J., Lupoglazoff, J.-M., Mabo, P., Veltmann, C., Jesel, L., Chevalier, P., Clur, S.A.B., Haissaguerre, M., Wolpert, C., Le Marec, H. \& Wilde, A.A.M. (2007) Clinical aspects and prognosis of Brugada syndrome in children. Circulation 115, 2042-2048.

Sastry, B.K., Narasimhan, C. \& Soma, R.B. (2001) Brugada syndrome with monomorphic ventricular tachycardia in a one-year-old child. Indian Heart Journal 53, 203-205.

Suzuki, T. \& Koisaka, S. (2006) Brugada-type electrocardiographic changes in a febrile patient of african descent. American Journal of Medical Sciences 3322, 97-99.

Wakita, R., Watanabe, I., Okumura, Y., Yamada, T., Takagi, Y., Kofune, T., Okubo, K., Masaki, R., Sugimura, H., Oshikawa, N., Saito, S., Ozawa, Y. \& Kanmatsuse, K. (2004) Brugada-like electrocardiographic pattern unmasked by fever. Japanese Heart Journal 45, 163-167.

Yamakawa, Y., Ishikawa, T., Uchino, K., Mochida, Y., Ebina, T., Sumita, S., Kobayashi, T., Matsushita, K., Matsumoto, K., Ohkusu, Y., Nishizawa, T., Takigiku, K., Iwamoto, M., Kimura, K. \& Umemura, S. (2004) Prevalence of right bundle-branch block and right precordial ST-segment elevation (Brugada-type electrocardiogram) in Japanese children. Circulation Journal 68, 275-279.

Zipes, D.P., Camm, A.J., Borggrefe, M., Buxton, A.E., Chaitman, B., Fromer, M., Gregoratos, G., Klein, G., Moss, A.J., Myerburg, R.J., Priori, S.G., Quinones, M.A., Roden, D.M., Silka, M.J., Tracy, C., Blanc, J.-J., Budaj, A., Dean, V., Deckers, J.W., Despres, C., Dickstein, K., Lekakis, J., McGregor, K., Metra, M., Morais, J., Osterspey, A., Tamargo, J.L., Zamorano, J.L., Smith, S.C., Jacobs, A.K., 
Adams, C.D., Antman, E.M., Anderson, J.L., Hunt, S.A., Halperin, J.L., Nishimura, R., Ornato, J.P., Page, R.L. \& Riegel, B. (2006) ACC/AHA/ESC 2006 guidelines for management of patients with ventricular arrhythmias and the prevention of sudden cardiac death: a report of the American College of Cardiology/American Heart Association Task Force and the European Society of Cardiology Com. Europace 8, 746-837. 